Central European Journal of Energetic Materials, 2016, 13(2), 527-544

ISSN 1733-7178

e-ISSN 2353-1843

\title{
1,1-Diamino-2,2-dinitroethene (DADNE, FOX-7) - Properties and Formulations (a Review)
}

\author{
Waldemar A. TRZCIŃSKI ${ }^{1 *}$, Amel BELAADA ${ }^{1,2}$ \\ ${ }^{1}$ Military University of Technology, \\ Kaliskiego 2, 00-908 Warsaw, Poland \\ ${ }^{2}$ Polytechnic Military School, \\ Bordj El Bahri, PB 17, 16111 Algiers, Algeria \\ ${ }^{*}$ E-mail: waldemar.trzcinski@wat.edu.pl
}

\begin{abstract}
A review of the available literature on the properties of 1,1-diamino-2,2dinitroethene (DADNE, FOX-7) and formulations containing FOX-7 is presented in this paper. The structural, thermal and spectroscopic properties as well as the sensitivity and explosive properties of FOX-7 are described. Compositions containing FOX-7 are characterized in details and their sensitivity and explosive properties are presented. Potential areas of application for such formulations have been identified.
\end{abstract}

Keywords: 1,1-diamino-2,2-dinitroethene (DADNE, FOX-7), FOX-7-based formulations, performance, sensitivity, application

\section{Introduction}

In military applications, there is increasing interest in novel energetic materials with greater performance and lower sensitivity to stimuli, in order to increase the effectiveness of munitions and to reduce warhead vulnerability problems. It is generally believed that both of these factors are intimately connected with the presence of crystalline defects in the materials. In order to explore new energetic materials with these required properties, a promising method is to explore compounds with compact structures and a high nitrogen content, as demonstrated by many recent research and development efforts [1-6].

1,1-Diamino-2,2-dinitroethene $\left(\mathrm{C}_{2} \mathrm{H}_{4} \mathrm{~N}_{4} \mathrm{O}_{4}\right)$, also known as FOX-7 or 
DADNE, is commonly expected to be a promising explosive, combining comparatively high performance and low sensitivity. The unique characteristics of FOX-7 result from its molecular structure [7], which is beneficial for the creation of strong inter- and intra-molecular hydrogen bonds for stabilizing the molecule. Since 1998, when FOX-7 was first synthesized by Latypov et al. [8], it has been the subject of many experimental investigations [9-22]. FOX-7 has a favorable oxygen balance and the decomposition of the molecule can produce entirely gaseous products $\left(\mathrm{CO}, \mathrm{H}_{2} \mathrm{O}, \mathrm{N}_{2}\right)$. FOX-7 has been found to be far less sensitive to impact and shock than RDX (1,3,5-trinitro-1,3,5-triazinane), whereas its explosive properties are comparable to those of RDX. For these reasons FOX-7 has appeared to be very useful for systems in which its insensitivity is more important than maximum performance.

Routes for the synthesis of FOX-7, together with its structural, spectroscopic, and explosive properties have been comprehensively reviewed by Bellamy [23]. In the present review, a condensed account of the main features of FOX-7 will be presented prior to a review of explosive compositions based on this material.

\section{Properties of FOX-7}

\subsection{Structural, thermal and spectroscopic properties of FOX-7}

FOX-7 is a bright yellow crystalline powder. It is only slightly soluble in common organic solvents and water but readily dissolves in dipolar aprotic solvents such as dimethylsulphoxide, $\mathrm{N}, \mathrm{N}$-dimethylformamide and $\mathrm{N}$-methyl-2-pyrrolidinone (NMP) [20].

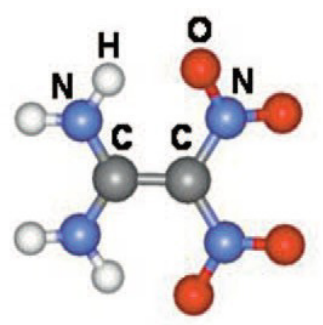

Figure 1. Molecular structure of FOX-7 [24]. The $\mathrm{C}$ atoms are shown in gray, $\mathrm{O}$ in red, $\mathrm{N}$ in blue, $\mathrm{H}$ in white.

The molecular structure of FOX-7 is shown in Figure 1 [24]. The compound is a characteristic so-called "push-pull" alkene [25]. The length of the bond between carbon atoms in the molecule $(1.456 \AA)$ is intermediate between the length of a normal single bond (1.54 $\AA$ ) and a normal double bond (1.34 $\AA$ ). 
The lengths of the $\mathrm{C}-\mathrm{NO}_{2}$ bonds (1.42 and $1.39 \AA$ ) are close to the normal bond length of nitrogen-carbon with $\mathrm{sp}^{2}$ hybridization (1.40), but the $\mathrm{C}-\mathrm{NH}_{2}$ bonds $(1.31$ and $1.32 \AA)$ are shorter by about $0.1 \AA$. The molecule has a generally planar structure.

The crystal structure of FOX-7 was determined in [7] as monoclinic with space group $P 2_{1} / n$ and four molecules and 56 atoms per unit cell (Figure 2, [24]). The values of the lattice parameters determined experimentally in [7] are: $a=6.9410 \AA, b=6.5690 \AA, c=11.315 \AA$, and $\beta=90.55^{\circ}$. The crystal density is $1.907 \mathrm{~g} / \mathrm{cm}^{3}$. Slightly different values of these parameters as determined experimentally and theoretically are presented in [26]. FOX-7 can exist in many tautomers and presents different structural forms under different conditions [27].

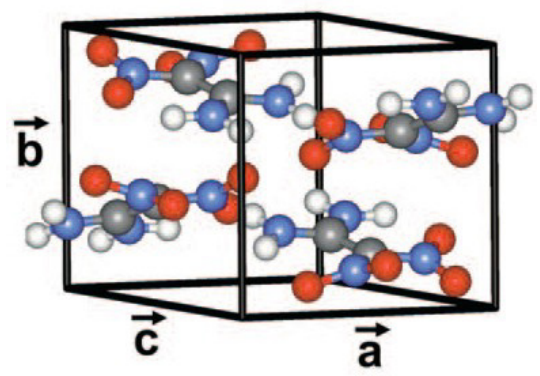

Figure 2. The ideal crystalline structures of FOX-7 [24]. The translation vectors of the crystalline structure are also indicated.

The crystal structure of FOX-7 consists of molecules aligned end-to-end in an infinite two-dimensional wave shape (Figure 3 [24]) with intra-layer hydrogen bonding and inter-layer van der Waals interactions [28]. The distance between layers is $\sim 3 \AA$. The results of more detailed studies of the crystal structure of $\alpha-$, $\beta$ - and $\gamma$-FOX-7 by X-ray single crystal and powder investigations are reported in [29] and [30].

The molecular packing structure with strong intra- and inter-molecular hydrogen bonding explains some of the physicochemical properties of FOX-7, in particular its low solubility, low sensitivity to impact and friction and lack of a melting point [11]. Stress inside the crystal is reduced by the movement of two layers. In this manner the crystal becomes more insensitive towards mechanical strain [20]. 

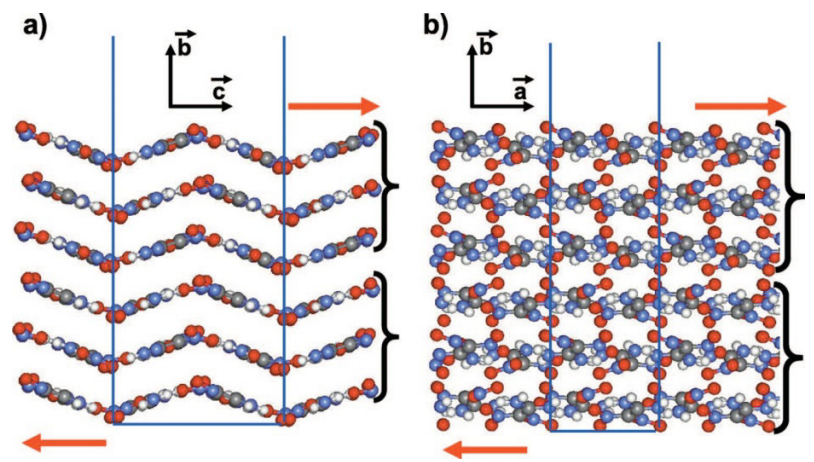

Figure 3. Wave-shaped layers of the crystal structure of FOX-7: a) $\boldsymbol{a} \boldsymbol{b}$ plane; b) $\boldsymbol{b c}$ plane. The thin blue lines indicate the size of the periodic cell along the $\boldsymbol{a}$ and $\boldsymbol{c}$ translational lattice vectors. The red arrows show the directions of the applied shear-strain deformation [24].

Using X-ray diffraction and thermal analysis techniques it was proved that heated FOX-7 can be in three [31,32] or four [33] polytropic phases $(\alpha, \beta, \gamma$ or $\delta$ ). The $\alpha$-phase is stable at room temperature. The first reversible phase transition $(\alpha \beta)$ occurs at $113{ }^{\circ} \mathrm{C}$ [32] or $90{ }^{\circ} \mathrm{C}$ [33] and is accompanied by a volume increase of $1.9 \%$ [32]. A second transition $(\beta \rightarrow \gamma)$ occurs at $173{ }^{\circ} \mathrm{C}$ [32] or $115^{\circ} \mathrm{C}$ [33] and a further transition $(\gamma \rightarrow \delta)$ occurred at $155^{\circ} \mathrm{C}$ [33]. The inverse transitions at different temperatures are reported in [32-33]. The discrepancies in the temperatures of phase transition and decompositions reported by various authors are associated with the different methods of preparation of the samples tested, the type of solvent used for the FOX-7 crystallization [34], and the fineness of the crystals [33].

Further heating of FOX-7 results in its decomposition, which occurs in two stages at temperatures $T_{d}$ of approx. $235^{\circ} \mathrm{C}$ and $280^{\circ} \mathrm{C}$ [35]. The position of the decomposition peaks may occur at other temperatures, depending on the history of the preparation and recrystallization of the FOX-7 and the heating rate of the samples (Figure 4 [36]). TG results show that the mass losses associated with the two exothermic peaks are $\sim 38 \%$ for low temperature peak, and $\sim 45 \%$ for the high temperature peak [37]. The activation energy $E_{a}=257.6 \mathrm{~kJ} / \mathrm{mol}$ for the temperature interval $215-230{ }^{\circ} \mathrm{C}$ was measured in [36] from the DTA curves, with $E_{a}=468.0 \mathrm{~kJ} / \mathrm{mol}$ for the interval $276-283{ }^{\circ} \mathrm{C}$. The apparent activation energies obtained from DSC data are $238.3 \mathrm{~kJ} / \mathrm{mol}$ for the first decomposition peak (the temperature interval $202.3-249.5^{\circ} \mathrm{C}$ ) and $322.4 \mathrm{~kJ} / \mathrm{mol}$ for the second peak (the interval $261.7-278.8^{\circ} \mathrm{C}$ ) [38]. 


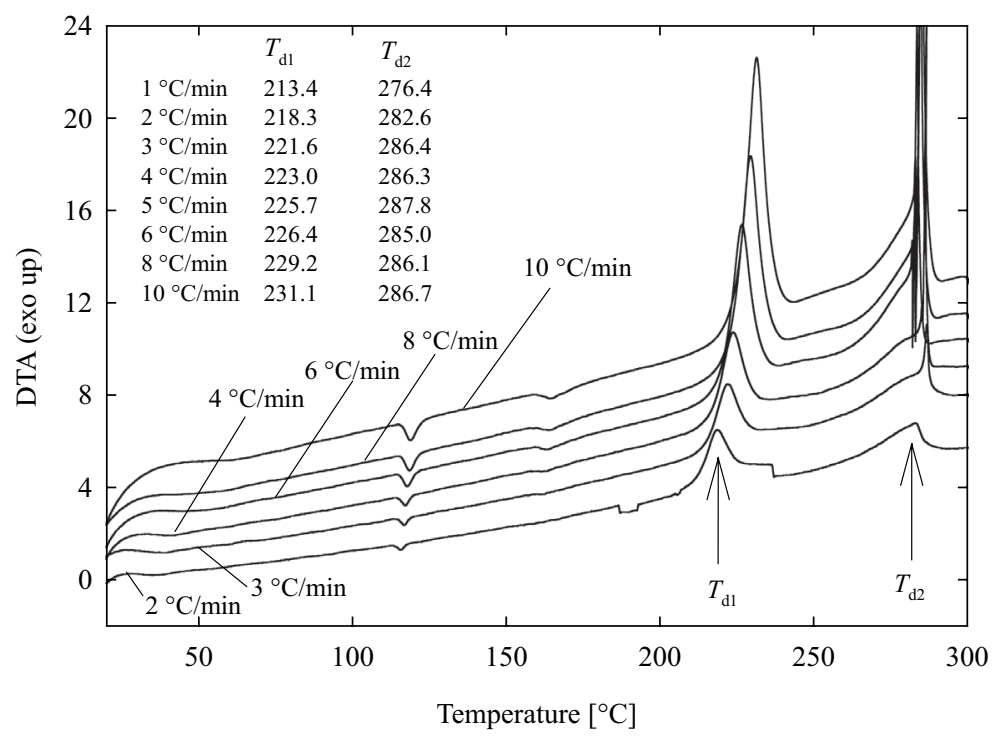

Figure 4. DTA (5 g sample) of recrystallized FOX-7 [36].

Nuclear magnetic resonance (NMR) spectroscopic data for FOX-7 were obtained in dimethylsulphoxide $\left(\mathrm{DMSO}-\mathrm{d}_{6}\right)[8,20,37,39]$. The ${ }^{1} \mathrm{H}$ NMR spectrum (Figure 5a) shows a single broad peak (at $8.77 \mathrm{ppm}$ ) for the four hydrogen atoms of the two amino groups. The ${ }^{13} \mathrm{C}$ NMR spectrum (Figure $5 \mathrm{~b}$ ) shows 2 signals, with the carbon bearing the amino groups appearing at 128.4 and the carbon bearing the nitro groups appearing at $158.4 \mathrm{ppm}$ [39]. In the ${ }^{15} \mathrm{~N}$ NMR spectrum, absorptions occur at $108.6\left(\mathrm{NO}_{2}\right)$ and $356.0 \mathrm{ppm}\left(\mathrm{NH}_{2}\right)$ (liquid ammonia was used as an external reference - [39]). In other researches, the ${ }^{1} \mathrm{H}$ NMR spectrum exhibited a single peak at $8.77 \mathrm{ppm}[8], 8.64 \mathrm{ppm}$ [20] or $8.55 \mathrm{ppm}$ [37] and the ${ }^{13} \mathrm{C}$ NMR spectrum exhibited 2 peaks at $128.5 \mathrm{ppm}$ [8], $128.1 \mathrm{ppm}$ [20] or $129.1 \mathrm{ppm}$ [37] and $158.8 \mathrm{ppm}$ [8], $158.3 \mathrm{ppm}$ [20] or $157.9 \mathrm{ppm}[37]$.

The infrared spectrum of FOX-7 shows absorbances in the 3200-3400 and $1350-1650 \mathrm{~cm}^{-1}$ ranges, which are characteristic of the amino and nitro functionalities respectively [8]. The Raman spectrum of solid FOX-7 was shown in [23]. A mass spectroscopic study was reported in [33]. FOX-7 gives a very strong molecular peak $(\mathrm{m} / \mathrm{z} 148)$ in the mass spectrum at $70 \mathrm{eV}$. This indicates that the FOX-7 molecule is more stable than RDX, TNT, and NTO. Numerous other minor peaks were also observed in [33]. 

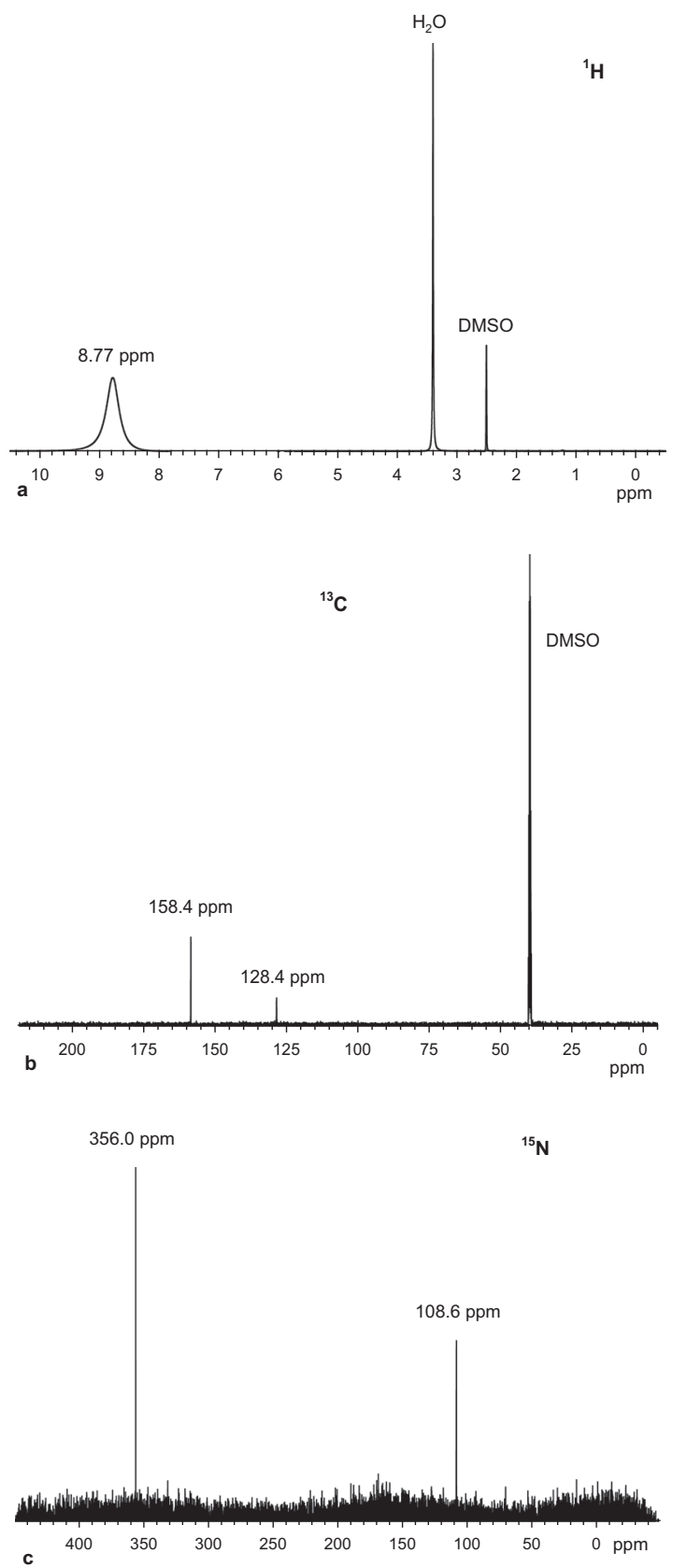

Figure 5. a) ${ }^{1} \mathrm{H}$ NMR spectrum of FOX-7, b) ${ }^{13} \mathrm{C}$ NMR spectrum of FOX-7, c) ${ }^{15} \mathrm{~N}$ NMR spectrum of FOX-7. 
The results from research on the application of thin layer chromatography (TLC) and high performance liquid chromatography (HPLC) for the determination of FOX-7 and its precursors produced in the synthetic path starting from 2-methylpyrimidine-4,6(1H,5H)-dione were presented in [40] and [5], respectively. The analytical parameters of the substances and the methodology for their quantitative analysis were determined, and the results obtained were used for monitoring the FOX-7 synthetic process.

\subsection{Sensitivity and explosive properties of FOX-7}

The stabilizing effect of hydrogen bonding and resonance effects cause FOX-7 to be one of the less sensitive explosives. The friction sensitivity tests using a Julius-Peters machine demonstrated that, even with a load of $353 \mathrm{~N}$, samples of FOX-7 were insensitive, regardless of their particle size $[9,11,22]$.

The impact sensitivity of FOX-7 was reported in the literature using a testing apparatus with a 2 or $5 \mathrm{~kg}$ hammer. The highest drop height is usually determined at which no reaction is observed in several consecutive tests (a socalled high limit of insensitivity). In [10], the limiting impact energy of $15.5 \mathrm{~J}$ and 12.4 J was determined for FOX-7 crystals with sizes of $250-355 \mu \mathrm{m}$ and less than $70 \mu \mathrm{m}$, respectively. The limiting energy $11.3 \mathrm{~J}$ was found for coarse FOX-7 recrystallized in a water/NMP mixture (crystals with size 250-300 $\mu \mathrm{m}$ dominated) [22]. The impact sensitivity can also be expressed as the drop height at which $50 \%$ initiations occurred. The corresponding impact energy, denoted as $E_{50}$, was reported in [9] and [11]. Values of $24 \mathrm{~J}$ and $31.2 \mathrm{~J}$ were found for unrecrystallized FOX-7 and recrystallized FOX-7 (330-450 $\mu \mathrm{m})$, respectively. The impact energy $E_{50}=17.3 \mathrm{~J}$ was obtained for coarse-grain FOX-7 in [22].

The shock sensitivity results for FOX-7 reported in the literature are ambiguous. The shock sensitivity of pressed FOX-7 determined in [9] and [11] was lower than that of TNT. Fine-grain FOX-7 in [22] was also less sensitive than TNT, but coarse-grain FOX-7 was much more sensitive. From the data given in [12] it follows that the critical pressure for the initiation of FOX-7 (1.05 GPa) is lower than that for TNT $(1.40 \mathrm{GPa})$.

The electrostatic discharge (ESD) test is a safety test to screen the response of an energetic material to electrostatic discharges of $4.5 \mathrm{~J}, 0.45 \mathrm{~J}$ and $0.045 \mathrm{~J}$. Ignition occurs at $4.5 \mathrm{~J}$ but not at $0.45 \mathrm{~J}$ for both FOX-7 and RDX [41].

In the Koenen test, the heat sensitivity of an explosive is expressed as the largest diameter of the nozzle plate hole at which at least one explosion occurs out of three consecutive tests. For FOX-7 the diameter is $6 \mathrm{~mm}$, the first low order reaction damaging the confinement occurs at a nozzle diameter $6 \mathrm{~mm}$ (type "F" effect). RDX was more sensitive in this test, resulting in an explosion at 
$8 \mathrm{~mm}$ nozzle diameter [11].

The detonation performance of FOX-7 was determined in [22]. The detonation velocity and pressure of FOX-7 were measured for charges of $25 \mathrm{~mm}$ diameter and a density of $1780 \mathrm{~kg} / \mathrm{m}^{3}$ placed in a water envelope. A velocity of $8390 \mathrm{~m} / \mathrm{s}$ and a pressure of $28.8 \mathrm{GPa}$ were obtained. For charges of $20 \mathrm{~mm}$ diameter without any envelope, the measured detonation velocity was $8325 \mathrm{~m} / \mathrm{s}$. The Gurney velocity and the detonation energy estimated from the results of a cylinder test were $2660 \mathrm{~m} / \mathrm{s}$ and $4980 \mathrm{~J} / \mathrm{g}$, respectively. The latter was slightly higher than the calorimetric heat of detonation $(4860 \mathrm{~J} / \mathrm{g})$. The results of the cylinder test were used in [22] for the determination of the constants of the JWL (Jones, Wilkins, Lee) equation of state for the detonation products of FOX-7.

The cylinder test was also performed for FOX-7 phlegmatized with 1.5\% wax [10]. A detonation velocity $8335 \mathrm{~m} / \mathrm{s}$ was measured for FOX-7 charges of density $1756 \mathrm{~kg} / \mathrm{m}^{3}$. The asymptotic velocity of the standard copper tube was $1527 \mathrm{~m} / \mathrm{s}$, which corresponds to a Gurney velocity of ca. $2510 \mathrm{~m} / \mathrm{s}$ for the detonation products of FOX-7.

From the data given in the literature it follows that FOX-7 is much less sensitive than RDX to impact and shock, and very insensitive to friction. Its detonation performance is comparable to that of RDX. This is why FOX-7 is an attractive alternative to RDX [23].

\section{Compositions Based on FOX-7}

\subsection{Phlegmatized formulations and plastic bonded explosives}

Commonly used formulations of explosives are mixtures containing a few percent of a macromolecular substance of natural or artificial origin. Such substances are added to reduce the sensitivity (phlegmatizing) and to improve the capacity to form mechanically strong charges (binding) by compression. Plastic bonded explosives (PBXs) are powdered explosives to which plastic or polymeric binders have been added. Commonly, RDX or HMX are used as the explosive component. FOX-7 is proposed as a replacement for these explosive compounds.

Kretschmer et al. [42] investigated the chemical stability, sensitivity and mechanical and explosive properties of mixtures of FOX-7 or RDX with paraffin, ethylene-propylene rubber (EPM) and the polyacrylate elastomer (Hy Temp). The tested formulations contained $95 \%$ FOX-7 or RDX, $4.5 \%$ binder and $0.5 \%$ graphite. It was found that in terms resistance to heat and mechanical properties, the formulations with FOX-7 behaved similarly to the RDX-based ones. Mixtures containing FOX-7 could be pressed to higher densities $\left(\sim 1.77 \mathrm{~g} / \mathrm{cm}^{3}\right)$ than the 
compositions with $\operatorname{RDX}\left(\sim 1.7 \mathrm{~g} / \mathrm{cm}^{3}\right)$, but the detonation velocity of the former was lower by $\sim 100 \mathrm{~m} / \mathrm{s}$ (it varied in the range $8200-8450 \mathrm{~m} / \mathrm{s}$ depending on the type of binder). By contrast, the FOX-7-based formulations were much safer, because their sensitivity to mechanical stimuli was much less than that of compositions containing RDX. Sensitivity to a shock wave was halved and was almost independent of the binder used. The impact sensitivity of FOX-7-based formulations were in general better than those containing RDX. However, the binder used affected the sensitivity, which varied from $\sim 7.5 \mathrm{~J}$ for compositions with HyTemp to $25 \mathrm{~J}$ for compositions with paraffin. The impact sensitivity of the RDX-based formulations with different binders varied from 6 to $10 \mathrm{~J}$.

FOX-7 phlegmatized with wax (2.2\%) was used in shaped charges in [43]. The properties of FOX-7 charges pressed isostatically were compared with that of Hexotol (60\% RDX and 40\% TNT) charges. The detonation performance of the FOX-7/wax mixture was slightly better than for Hexotol. The characteristics of the cumulative jet produced by the FOX-7 charge and its penetration ability were better than that determined for Hexotol.

In [44] mixtures of FOX-7 with RDX were phlegmatized with 2\% PTFE (polytetrafluoroethylene). The FOX-7 content was varied from 0 to $100 \%$. It was claimed that the impact and friction sensitivity of the composition decreased considerably when at least $60 \%$ FOX-7 was present. The addition of FOX-7 had little influence on the detonation velocity of mixtures with RDX.

The same phlegmatizing agent (PTFE) was applied in compositions containing $95 \%$ of mixtures of RDX/FOX-7 and HMX/FOX-7 in [45]. The crystals of FOX-7 used had a bulk density of $1.1 \mathrm{~g} / \mathrm{cm}^{3}$. The detonation velocity of the HMX/FOX-7 compositions decreased with increasing FOX-7 content (from 8570 to $8220 \mathrm{~m} / \mathrm{s}$ for 0 and $100 \%$ FOX-7, respectively). The application of FOX-7 as an additive in the compositions with RDX does not cause a decrease in the detonation velocity. The blast capacity was also measured from a determination of the evolution of the blast wave in air after detonation of the tested mixtures. The results showed that the blast overpressure peak and the positive phase impulse decreased with increasing FOX-7 content. However, the decrease in the impulse was much smaller than the decrease in the overpressure peak.

The authors of [41] and [46] tested FOX-7 coated with 5\% EVA polymer (poly[ethylene-co-vinyl acetate], 40\% vinyl acetate) as a potential booster formulation. SEM analysis of the granules obtained, 100-500 $\mu \mathrm{m}$ in size, showed that the coating on the agglomerated particles was not homogeneous [41]. Grade A RDX was also coated with EVA for comparative tests.

The detonation velocity and pressure of FOX-7/EVA formulations were determined using cylindrical charges of $12.7 \mathrm{~mm}$ diameter and density 
$1.645 \mathrm{~g} / \mathrm{cm}^{3}$ (92\% TMD) [41]. The relative detonation pressure was estimated from the dent depth in the steel witness plate. The detonation velocity and pressure were $7730 \mathrm{~m} / \mathrm{s}$ and $24.1 \mathrm{GPa}$, respectively. The velocity for the FOX-7/ EVA charges was $100 \mathrm{~m} / \mathrm{s}$ higher than that for RDX/EVA charges.

Testing of the performance and sensitivity of the FOX-7/EVA formulations was continued in [46]. The detonation velocity and pressure were measured for charges of $25 \mathrm{~mm}$ diameter and density $1.686 \mathrm{~g} / \mathrm{cm}^{3}$ (94.3\% TMD). Values of $8110 \mathrm{~m} / \mathrm{s}$ and $25.1 \mathrm{GPa}$, respectively, were obtained. In this case, the detonation velocity was about $2 \%$ lower and the detonation pressure was about $8 \%$ lower compared with the corresponding parameters measured for the RDX/EVA formulation with approximately the same percentage of TMD.

The response of FOX-7/EVA and RDX/EVA formulations to fast and slow cook-off tests was assessed in [46] using the MRL super small-scale cook-off bomb (SSCB) [47]. The results obtained clearly demonstrated that FOX-7/EVA reacts at higher temperatures with notably milder responses than an equivalent RDX formulation (reaction type: mild burn and burn versus detonation and deflagration). The MRL small-scale test (SSGT) [48] was used for the determination of the shock sensitivity of FOX-7/EVA and RDX/EVA formulations. The shock sensitivity of FOX-7/EVA was lower than that of RDX/EVA.

The initial results for FOX-7 phlegmatised with a polyethylene wax (PE-wax) are also presented in [46]. The formulation of FOX-7 coated with 5\% PE exhibited low shock sensitivity, significantly below that of the equivalent RDX formulation and also the FOX-7/EVA formulation. Moreover, FOX-7 coated with $1.25 \%$ PE wax was used in the SSGT and cook-off tests. The shock sensitivity of the FOX-7 formulation was much lower than that of the comparable RDX formulation. As for the FOX-7/EVA explosives, the FOX-7/PE wax formulation also gave burn/mild burn responses, and reacted much less violently that the equivalent $\mathrm{RDX}$ formulation.

In order to improve the mechanical properties of pressed FOX-7 and to increase the performance, formulations containing Viton-coated bimodal FOX-7 and HMX were tested in [49]. A mixture of FOX-7 composed of $70 \mathrm{wt} . \%$ of the large size fraction $(250-500 \mathrm{~mm})$ and $30 \mathrm{wt} . \%$ of the small size fraction $(5-11 \mathrm{~mm})$ was used to obtain high density and tough pressed charges. The particles in this mixture were coated with $6 \%$ of Viton A and the explosive formulation FOX- $7_{\text {Vit }}$ was obtained. A second explosive was a mixture containing 30\% fine particles of FOX-7, 40\% coarse particles of FOX-7, and 30\% HMX (150 to $450 \mathrm{~mm}$ particles). This mixture was also phlegmatized with Viton A (FOX-7/HMX) $)_{\mathrm{Vit}}$. The sensitivity to impact, friction, and shock were determined for these new 
formulations, and the detonation and energetic characteristics were estimated in water and cylinder tests. The parameters obtained were compared with the detonation performance of RDX phlegmatized with $6 \%$ of wax $\left(\mathrm{RDX}_{\mathrm{ph}}\right)$. The thermal stability of these new explosive formulations and the compatibility of their components were established using thermogravimetric analysis and differential thermal analysis (TGA/DTA).

The experimental parameters of the formulations tested in [49] are summarized in Table 1 . The symbols $D, P_{\mathrm{CJ}}, E_{0}, Q_{\mathrm{d}}$, and $E_{\mathrm{G}}$ denote the detonation velocity, pressure, and energy, the calorimetric heat of detonation, and the Gurney energy, respectively. The detonation pressure, velocity, and energy, as well as the Gurney energy of the FOX-7-based compositions are comparable to or even higher than those of RDX phlegmatized with wax. However, the energetic characteristics of the formulations with FOX-7 (the energy and heat of detonation) are lower than those determined for $\mathrm{RDX}_{\mathrm{ph}}$.

Table 1. Measured and calculated detonation properties of the formulations tested in [49]

\begin{tabular}{|l|c|c|c|c|c|c|}
\hline Explosive & $\begin{array}{c}\text { Density } \\
{\left[\mathrm{kg} / \mathrm{m}^{3}\right]}\end{array}$ & $\begin{array}{c}D \\
[\mathrm{~m} / \mathrm{s}])\end{array}$ & $\begin{array}{c}P_{\mathrm{CJ}} \\
{[\mathrm{GPa})}\end{array}$ & $\begin{array}{c}E_{0} \\
{[\mathrm{~J} / \mathrm{g}]}\end{array}$ & $\begin{array}{c}Q_{\mathrm{d}} \\
{[\mathrm{J} / \mathrm{g}]}\end{array}$ & $\begin{array}{c}E_{\mathrm{G}} \\
{[\mathrm{J} / \mathrm{g}]}\end{array}$ \\
\hline RDX $_{\text {ph }}$ & 1630 & 8300 & 26 & 5340 & 5340 & 3730 \\
\hline FOX-7 & 1790 & 8300 & 28 & 4960 & 4590 & 3520 \\
\hline$($ FOX-7/HMX) & 1800 & 8500 & 31 & 5220 & 4940 & 3730 \\
\hline
\end{tabular}

The sensitivity of phlegmatized FOX-7 to mechanical stimuli (shock, impact, and friction) was comparable or even less than the sensitivity of TNT. The composition of FOX-7 and HMX with particles covered properly by a phlegmatizing agent was less sensitive than phlegmatized RDX.

The thermal decomposition of the phlegmatized samples occurred in a similar manner to the decomposition of pure FOX-7. The presence of Viton A resulted in a significant decrease in the rate of the first stage of FOX-7 decomposition and did not influence the onset temperature of decomposition. HMX was fully compatible with FOX-7.

According to the authors of [49], the detonation performance obtained, the sensitivity and the thermal behaviour of the tested explosives, indicated that it is possible to formulate explosive compositions containing FOX-7 which can be qualified as safe high explosives. Due to their powdery form, they can be formed into charges by pressing. 


\subsection{Cased-cured formulations}

Cased-cured formulations based on FOX-7 and containing energetic binders were developed and tested at the Swedish Defence Research Agency (FOI) [10, 50-53]. These formulations are expected to replace Composition $\mathrm{B}$ because there are some disadvantages with the latter, i.e. relatively poor impact sensitivity and a somewhat violent reaction during cook-off. Thermochemical calculations showed that PBXs composed of $70 \mathrm{wt} . \%$ of bimodal FOX-7 (71 wt.\% of the size fraction $250-500 \mathrm{~mm}$ and $29 \mathrm{wt} . \%$ of the size fraction $<70 \mathrm{~mm}$ ) and $30 \mathrm{wt} . \%$ of a polymer, for example, polyglycidyl nitrate (PolyGLYN), polyglycidyl azide (GAP), should have detonation parameters similar to those of Composition B. Additionally, $30 \%$ of the binder in the mixture is sufficient to make it viscous and castable before curing. The properties of a formulation consisting of $70 \%$ of FOX-7 and 30\% of a binder composed of PolyGLYN (70.6\%), plasticizer BuNENA (17.6\%) and curing agents $\mathrm{H}_{12} \mathrm{MDI}(11.8 \%$ ) and DBTDL (below $0.01 \%$ ), were described in [10] and [50]. The formulation, designated as FOF-2, showed no friction sensitivity but it was more sensitive to impact than its respective components. No transition from deflagration to detonation was observed in steel tubes with a diameter of $25 \mathrm{~mm}$. The composition did not react violently during slow heating $\left(3.3^{\circ} \mathrm{C} / \mathrm{h}\right)$ in the slow cook-off test. It burned without destruction of the container. The castable composition of FOX-7 and polyGLYN showed low-sensitivity properties but the mechanical properties were inadequate; it was very stiff and non-elastic.

Another FOX-7-based PBX with improved castability (reduced viscosity) and mechanical properties (higher loading) was made by using a binder composed of $50 \mathrm{wt} . \%$ polyGLYN and $50 \mathrm{wt} . \%$ GAP [51]. Bimodal FOX-7 consisting of $50 \%$ of the size fraction $350-800 \mathrm{~mm}$ and $50 \%$ of the fraction $<70 \mathrm{~mm}$ was used. This new PBX, designated as FOF-3, was easily cast and when cured showed improved elastic properties. However this formulation had lower performance than FOF-2 [52].

To increase the performance, HMX was added to these FOX-7 formulations [52-53]. The first PBX, designated as FOF-4, contained $65.4 \mathrm{wt} . \%$ FOX-7 (particle size $350-800 \mathrm{~mm}$ ), $14 \mathrm{wt} . \%$ HMX (22 mm) and $20.6 \mathrm{wt} . \%$ of a binder with PolyGLYN and GAP. The formulation FOF-4 had improved performance but also high viscosity due to the broad particle size distribution.

Another PBX contained $16.5 \mathrm{wt} . \% \mathrm{HMX}(22 \mathrm{~mm})$ and $63.5 \mathrm{wt} . \%$ of bimodal FOX-7 (60\% of mean size $238 \mathrm{~mm}$ and $40 \%$ of mean size $32 \mathrm{~mm}$ ) [53]. A binder composed of polyGLYN and GAP was used. This PBX, designated as FOF-5, show much lower response to a slow cook-off test (fire or deflagration), a fast cook-off test (deflagration) and a bullet impact test (fire) than Composition B 
(detonation in all the above tests). The cast-cured explosive FOF-5 has the same calculated performance as Composition B.

\subsection{Melt-cast compositions}

In [54], FOX-7 was evaluated as a possible replacement for RDX in TNT-based melt-cast formulations. Details of the FOX-7 and RDX based formulations are shown in Table 2. The compositions were obtained by the standard, meltcast technique involving the addition of RDX or FOX-7 to molten TNT with continuous stirring. After cooling, the charge was extracted from the mould and machined to the required size.

Table 2. Formulations tested in [54]

\begin{tabular}{|c|c|c|c|c|}
\hline Formulation & RDX & FOX-7 & TNT & Al \\
\hline FT & - & 30 & 70 & - \\
\hline RT & 30 & - & 70 & - \\
\hline FTA & - & 25 & 60 & 15 \\
\hline RTA & 25 & - & 60 & 15 \\
\hline
\end{tabular}

Thermal decomposition studies of these formulations were carried out using the DSC technique. It was inferred from the peak temperatures of the FOX-7 formulations that TNT and FOX-7 decompose as a mixture at a temperature of about $256.8^{\circ} \mathrm{C}$ and $252.4{ }^{\circ} \mathrm{C}$ for the non-aluminized FT and the aluminized FTA compositions, respectively. These temperatures are slightly lower than the decomposition temperature of FOX-7 $\left(264.2^{\circ} \mathrm{C}\right)$. On the other hand, the nonaluminized and the aluminized RDX-based formulations decompose at $231.6^{\circ} \mathrm{C}$ and $231.3^{\circ} \mathrm{C}$, respectively, which are lower than the decomposition temperature of $\mathrm{RDX}\left(\sim 238^{\circ} \mathrm{C}\right)$. According to the authors [54], these observations indicate that the formulations FOX-7/TNT have a greater thermal stability than the RDX/ TNT formulations.

The impact sensitivity of the explosive compositions was determined using the fall hammer method ( $2 \mathrm{~kg}$ drop weight). The Bruceton staircase approach was applied and the results were given in terms of the statistically obtained $50 \%$ probability of explosion $\left(h_{50}\right)$. The shock sensitivity was determined by the card gap test in which cellulose acetate sheets were used as the attenuator. The thickness of the cellulose sheets was varied until "no-go" was observed on the witness plate. The shock sensitivity was reported in terms of the minimum pressure of the shock wave that can initiate detonation of the tested explosive. The detonation velocity was measured using the ionization probe technique. The results of the performance and sensitivity tests for the tested formulations 
were compared to those for TNT.

The detonation velocity of the FOX-7-based formulation FT was $7061 \mathrm{~m} / \mathrm{s}$, lower than that found for the RDX-based formulation RT $(7230 \mathrm{~m} / \mathrm{s})$. The detonation velocity of the aluminized compositions were lower, by $200-300 \mathrm{~m} / \mathrm{s}$, compared with the non-aluminized compositions. The FOX-7-based aluminized and non-aluminized formulations were found to be more shock insensitive than the corresponding RDX-based formulations. However, they were more shock sensitive than melt-cast TNT itself. On the other hand, the compositions containing FOX-7 were less sensitive to friction and impact stimuli than TNT.

\subsection{Propellants}

The thermodynamic calculations and investigations of some aluminized binder/AP composite propellants containing FOX-7 and a comparison of their properties with those of a propellant without FOX-7 were reported in [55]. The introduction of FOX -7 instead of ammonium perchlorate caused a decrease in the burning temperature, heat of combustion, specific impulse and the burning rate of the propellant.

In order to decrease the detonatability of the propellants, FOX-7 was introduced into an aluminized composite propellant instead of HMX [56]. From the thermochemical calculations it follows that the propellant containing $22 \%$ of FOX-7 has a comparable deflagration temperature and the same volume of gaseous products as the propellant containing $22 \%$ of HMX. The experimental heat of combustion and linear burning rate of the propellant with FOX-7 were lower than that determined for the propellant with HMX. However the composite propellant containing $22 \%$ FOX-7 did not detonate when boosted with a pressed RDX/TNT mixture of $14 \mathrm{~g}$ weight. The propellant with HMX detonated under the same conditions.

\section{Conclusions}

This review of the literature shows that the properties of FOX-7 are still actively studied. The degree of sensitivity and the performance should make FOX-7 a good candidate as a component in explosive compositions with reduced sensitivity. From this survey it follows that attempts are being made to use FOX-7 in such compositions as phlegmatized formulations, plastic bonded explosives, cased-cured formulations, melt-cast compositions, and propellants. FOX-7 usually replaces RDX in these compositions. The sensitivity and detonation parameters of the new compositions are often compared with the corresponding 
properties of RDX-based formulations. While the sensitivity of compositions containing FOX-7 is lower than the sensitivity of the formulations with RDX, their detonation characteristics are lower. It seems that the most promising areas are cased-cured and melt-cast formulations, which can be used in mortar and artillery ammunition.

\section{References}

[1] Sikder A.K., Sikder N., A Review of Advanced High Performance, Insensitive and Thermally Stable Energetic Materials Emerging for Military and Space Applications, J. Hazard. Mater., 2004, A112, 1-15.

[2] Millar R.W., Philbin S.P., Claridge R.P., Hamid J., Studies of Novel Heterocyclic Insensitive High Explosive Compounds: Pyridines, Pyrimidines, Pyrazines and Their Bicyclic Analogues, Propellants Explos. Pyrotech., 2004, 29(2), 81-92.

[3] Chapman R.D., Wilson W.S., Fronabarger J.W., Merwin L.H., Ostrom G.S., Prospects of Fused Polycyclic Nitroazines as Thermally Insensitive Energetic Materials, Thermochim. Acta, 2002, 384(1-2), 229-243.

[4] Singh R.P., Verma R.D., Meshri D.T., Shreeve J.M., Energetic Nitrogen-rich Salts and Ionic Liquids, Angew. Chem. Int. Ed., 2006, 45, 3584-3601.

[5] Buszewski B., Michel M., Cudziło S., Chyłek Z., High Performance Liquid Chromatography of 1,1-Diamino-2,2-dinitroethene and some Intermediate Products of Its Synthesis, J. Hazard. Mater., 2009, 164, 1051-1058.

[6] Nair U.R., Asthana S.N., Subhananda Rao A., Gandhe B.R., Advances in High Energy Materials, Defence Sci. J., 2010, 60(2), 137-151.

[7] Bemm U., Ostmark H., 1,1-Diamino-2,2-dinitroethylene - a Novel Energetic Material with Infinite Layers in Two Dimensions, Acta Crystallogr., 1998, C54, 1997-1998.

[8] Latypov N., Bergman J., Langlet A., Wellmar U., Bemm U., Synthesis and Reactions of 1,1-Diamino-2,2-dinitroethylene, Tetrahedron, 1998, 54, 11525-11536.

[9] Ostmark H., Langlet A., Berman H., Wingborg N., Wellmar U., Bemm U., FOX7 - a New Explosive with Low Sensitivity and High Performance, $11^{\text {th }}$ Int. Symp. Detonation, Snow Mass, Colorado, August 31 - September 4, 1998.

[10] Karlsson S., Ostmark H., Eldsater C., Carlsson T., Bergman H., Wallin S., Pettersson A., Detonation and Sensitivity Properties of FOX-7 and Formulations Containing FOX-7, $12^{\text {th }}$ Int. Symp. Detonation, San Diego, California, August 11-16, 2002.

[11] Janzon B., Bergman H., Eldsater C., Lamnevik C., Ostmark H., FOX-7 - a Novel, High Performance, Low Vulnerability High Explosive for Warhead Applications, $20^{\text {th }}$ Int. Symp. Ballistics, Orlando, Florida, September 23-27, 2002.

[12] Matyushin Y.N., Afanas'ev G.T., Lebedev V.P., Mahov M.N., Pepekin V.I., TATB and FOX-7: Thermochemistry, Performance, Detonability, Sensitivity, $34^{\text {th }}$ Int. Annu. Conf. ICT, Karlsruhe, Germany, June 24-27, 2003. 
[13] Cudziło S., Kicinski W., Synthesis and Properties of DADNE (in Polish), Biuletyn WAT, 2004, 53(2-3), 183-204.

[14] Bellamy A.J., Latypov N.V., Goede P., Studies on the Nitration of New Potential Precursors for FOX-7, New Trends Res. Energ. Mater., Proc. Semin., $7^{\text {th }}$, Pardubice, Czech Republic, April 20-22, 2004.

[15] Chyłek Z., Cudziło S., Błądek J., Pietrzyk S., Optimization of 1,1-Diamino-2,2dinitroethene Synthesis (in Polish), Biuletyn WAT, 2005, 54(5-6), 19-16.

[16] Cudziło S., Chyłek Z., Diduszko R., Crystallization and Characterization of 1,1-Diamino-2,2-dinitroethene (DADNE) (in Polish), Biuletyn WAT, 2005, 54(5-6), $5-18$.

[17] Cudziło S., Chyłek Z., Diduszko R., Crystallization and Characterization of 1,1-Diamino-2,2-dinitroethene (DADNE), $36^{\text {th }}$ Int. Annu. Conf. ICT, Karlsruhe, Germany, June 28-July 1, 2005.

[18] Cudziło S., Chyłek Z., 1,1-Diamino-2,2-dinitroethene (DADNE), a New High Energetic and Low Sensitive Explosive (in Polish), Wiadomości Chemiczne, 2006, 60(11-12), 763-791.

[19] Trzciński W.A., Cudziło S., Chyłek Z., Szymańczyk L., Investigation of Sensitivity and Detonation Properties of FOX-7, $37^{\text {th }}$ Int. Annu. Conf. ICT, Karlsruhe, Germany, June 27-30, 2006.

[20] Anniyappan M., Talawar M.B., Gore G.M., Venugopalan S., Ganghe B.R., Synthesis, Characterization and Thermolysis of 1,1-Diamino-2,2-dinitroethylene (FOX-7) and Its Salts, J. Hazard. Mater., 2006, B137, 812-819.

[21] Trzciński W.A., Cudziło S., Chyłek Z., Szymańczyk L., Determination of the Expansion Isentrope for Detonation Products of FOX-7, $38^{\text {th }}$ Int. Annu. Conf. ICT, Karlsruhe, Germany, June 26-29, 2007.

[22] Trzciński W.A., Cudziło S., Chyłek Z., Szymańczyk L., Detonation Properties of 1,1-Diamino-2,2-dinitroethene (DADNE), J. Hazard. Mater., 2008, 157, 605-612.

[23] Bellamy A.J., FOX-7 (1,1-Diamino-2,2-dinitroethene), in: Structure and Bonding (Klapötke T.M., Ed.), Springer, Berlin, Heidelberg, 2007, 125, 1-33; ISSN: 00815993.

[24] Kuklja M.M., Rashkeev S.N., Shear-strain-induced Structural and Electronic Modifications of the Molecular Crystal 1,1-Diamino-2,2-dinitroethylene: Slip-plane Flow and Band Gap Relaxation, Phys. Rev. B, 2007, 75, 104111.

[25] Baum K., Bigelow S.S., Nguyen N.V., Archibald T.A., Gilardi R., FlippenAnderson J.L., Synthesis and Reactions of 1,1-Diiododinitroethylene, J. Org. Chem., 1992, 57(1), 235-241.

[26] Kuklja M.M., Zerilli F.J., Peiris S.M., Ab initio $0 \mathrm{~K}$ Isotherm for Crystalline 1,1-Diamino-2,2-dinitroethylene, J. Chem. Phys., 2003, 118(24),11073-11078.

[27] Xu K.-Z., Chang C.-R., Song J.-R., Zhao F.-Q., Ma H.-X., Lu X.-Q., Hu R.-Z., Crystal Structure and Theoretical Calculation of G(FOX-7), Chinese J. Chem., 2008, 26, 495-499.

[28] Hu A., Larade B., Rachid H.A., Lussier L.S., Guo H., A First Principles Density Functional Study of Crystalline FOX-7 Chemical Decomposition Process under 
External Pressure, Propellants Explos. Pyrotech., 2006, 31(5), 355-360.

[29] Evers J., Klapötke T.M., Mayer P., Oehlinger G., Welch J., $\alpha$ - and $\gamma$-FOX-7, Polymorphs of a High Energy Density Material, Studied by X-ray Single Crystal and Powder Investigations in the Temperature Range from 200 to $423 \mathrm{~K}$, Inorg. Chem., 2006, 45(13), 4996-5007.

[30] Crawford M-J., Evers J., Gębel M., Klapötke T.M., Mayer P., Oehlinger G., Welch J.M., $\gamma$-FOX-7: Structure of a High Energy Density Material Immediately Prior to Decomposition, Propellants Explos. Pyrotech., 2007, 32(6), 478-495.

[31] Kempa P.B., Herrmann M., Molina Metzger F.J., Thome V., Kjellstrom A., Latypov N., Phase Transition of FOX-7 Studied by X-ray Diffraction and Thermal Analysis, 35 th Int. Annu. Conf. ICT, Karlsruhe, Germany, June 29 - July 2, 2004.

[32] Kempa P.B., Herrmann M., Temperature Resolved X-ray Diffraction for the Investigation of the Phase Transitions of FOX-7, Part. Syst. Char., 2005, 22(6), 418-422.

[33] Ostmark H., Bergman H., Bemm U., Goede P., Holmgren E., Johansson M., Langlet A., Latypov N., Pettersson A., Pettersson M-L, Wingborg N., Vorde C., Stenmark H., Karlsson L., Hihkio M., 2,2-Dinitro-ethene-1,1-diamine (FOX-7) Properties, Analysis and Scale-up, $32^{\text {nd }}$ Int. Annu. Conf. ICT, Karlsruhe, Germany, July 3-6, 2001.

[34] Garmasheva N.V., Chemagina I.V., Filin V.P., Kazakova M.B., Loboiko B.G., Investigation of Diaminodinitroethylene, New Trends Res. Energ. Mater. Proc. Semin., $7^{\text {th }}$, Pardubice, Czech Republic, April 20-22, 2004.

[35] Garmasheva N.V., Chemagina I.V., Filin V.P., Kazakova M.B., Shakhtorin Y.A., Taybinov N.P., Lagutina V.M., Loboiko B.G., Research of Thermal Decomposition of Diaminodinitroethylene (FOX-7), $36^{\text {th }}$ Int. Annu. Conf. ICT \& $32^{\text {nd }}$ Int. Pyrotechnics Semin., Karlsruhe, Germany, June 28 - July 1, 2005.

[36] Cudziło S., Chyłek Z., Thermal Properties of 1,1-Diamino-2,2-dinitroethene (in Polish), $6^{\text {th }}$ Int. Armament Conf., Waplewo, Poland, October 11-13, 2006.

[37] Ticmanis U., Kaiser M., Pantel G., Fuhr I., Teipel U., Kinetics and Chemistry of Thermal Decomposition of FOX-7, $35^{\text {th }}$ Int. Annu. Conf. ICT, Karlsruhe, Germany, June 29 - July 2, 2004.

[38] Burnham A.K., Weese R.K., Wang R., Kwok Q.S.M., Jones D.E.G., Thermal Properties of FOX-7, $36^{\text {th }}$ Int. Annu. Conf. ICT, Karlsruhe, Germany, June 28- July 1, 2005.

[39] Szala M., Identification and Analysis of Explosives by Nuclear Magnetic Resonance Technique (in Polish), Military University of Technology, Warsaw, Poland, (manuscript ready for publication).

[40] Chyłek Z., Cudziło S., Błądek J., Pietrzyk S., Application of Thin Layer Chromatography for Monitoring of FOX-7 Synthesis, Propellants Explos. Pyrotech., 2009, 34(4), 321-325.

[41] Locher I.J., FOX-7 - A New Insensitive Explosive, DSTO-AR-1238, Aeronautical and Maritime Research Laboratory, Fishermans Bend, Australia, 2001.

[42] Kretschmer A., Gerber P., Happ A., Characterization of Plastic Bonded Explosive 
Charges Containing FOX-7, $35^{\text {th }}$ Int. Annu. Conf. ICT, Karlsruhe, Germany, June 29 - July 2, 2004.

[43] Helte A., Carlsson T.E., Wldsater C., Lundgren J., Ornhed H., Performance of FOX-7 (1,1-Diamino-2,2-dinitroethylene) in Shaped Charge Applications, $23^{\text {rd }}$ Int. Symp. Ballistics, Tarragona, Spain, April 16-20, 2007.

[44] Orzechowski A., Powała D., Maranda A., Florczak B., 1,1-Diamino-2,2dinitroethylene as a Component of Plastic Bonded Explosives, New Trends Res. Energ. Mater., Proc. Semin., 10 $0^{\text {th }}$, Pardubice, Czech Republic, April 25-27, 2007.

[45] Powała D., Orzechowski A., Maranda A., The Usable Parameters of PBX Containing FOX-7, New Trends Res. Energ. Mater., Proc. Semin., $13^{\text {th }}$, Pardubice, Czech Republic, April 21-23, 2010.

[46] Daniel M.A., Davies P.J., Lochert I.J., FOX-7 for Insensitive Boosters, DSTOTR-2449, Weapons System Division, Defense Science and Technology Organization, Edinburgh, Australia, 2010.

[47] Parker R.O., Establishment of a Super Small-scale Cookoff Bomb (SSCB) Test Facility at MRL, MRL-TR-89-9, Defense Science and Technology Organization, Edinburgh, Australia, 2009.

[48] Wolfson M.G., The MRL Small Scale Gap Test for the Assessment of Shock Sensitivity of High Explosives, MRL-R-896, Defense Science and Technology Organization, Edinburgh, Australia, 1983.

[49] Trzciński W.A., Chyłek Z., Cudziło S., Szymańczyk L., Detonation Properties and Thermal Behavior of FOX-7 Based Explosives, J. Energ. Mater., 2013, 31(10), $72-85$.

[50] Eldsäter C., Edvinsson H., Johansson M., Pettersson Å., Sandberd C., Formulation of PBX's Based on 1,1-Diamino-2,2-dinitroethylene (FOX-7), 33 ${ }^{\text {rd }}$ Int. Annu. Conf. ICT, Karlsruhe, Germany, June 23-28, 2002.

[51] Eldsäter C., Roman N., Development of Compositions Based on 1,1-Diamino-2,2dinitroethylene (FOX-7), 30 th Int. Pyrotechnic Semin., Saint Malo, France, June 23-27, 2003.

[52] Eldsäter C., Pettersson Å., Wanhatalo M., Formulation and Testing of a Comp B Replacement Based in FOX-7, Insensitive Munitions and Energetic Materials Symposium, San Francisco, California, USA, November 14-17, 2004.

[53] Bergman H., Pettersson Å., Östmark H., Stenmark H., Laitala C. B., FOX-7, an IM Ingredient Candidate - Where Are We Today?, Insensitive Munitions and Energetic Materials Technology Symposium, Tucson, Arizona, USA, May 11-14, 2009.

[54] Mishra V.S., Vadali S.R., Garg R.K., Joshi V.S., Wasnik R.D., Asthana S., Studies on FOX-7 Based Melt Cast High Explosive Formulations, Cent. Eur. J. Energ. Mater., 2013, 10(4), 569-580.

[55] Florczak B., Investigation of an Aluminized Binder/AP Composite Propellant Containing FOX-7, Cent. Eur. J. Energ. Mater., 2008, 5(3-4), 65-75.

[56] Florczak B., A Comparison of Properties of Aluminized Composite Propellant Containing HMX and FOX-7, Cent. Eur. J. Energ. Mater., 2008, 5(3-4), 103-111. 